\title{
Responsive Regulation and Taxation: Introduction
}

\author{
VALERIE BRAITHWAITE
}

\begin{abstract}
The implementation of responsive regulation in taxation means influencing the community's commitment to pay tax through respectful treatment, through attending to resistance and reforming faulty processes, through fairly directed and fully explained disapproval of non-compliant behavior, through preparedness to administer sanctions, and capacity to follow through to escalate regulatory intervention in the face of continuing non-compliance. Responsive regulation and regulatory formalism are pitted against each other in this issue on responsive regulation and taxation. Normative and explanatory arguments in favor of responsive regulation are explored by data collected in taxation contexts; and institutional obstacles are identified that limit effective implementation.
\end{abstract}

Taxation is a highly regulated activity. There are laws for paying tax, guides to its interpretation, an industry of tax practitioners to help us obey the law, armies of government bureaucrats to check that we are paying the right amount, and an elaborate system of sanctions from administrative penalties through legal proceedings to imprisonment to punish us should we err. If regulation entails directives to act in certain ways but not others, backed by enforcement practices, formalized as law and justified in terms of protecting the public interest, taxation should be at the center of the regulatory stage.

There are multiple reasons why this is not the case, arguably the most important being that we tend not to connect taxation with regulation as a process of "influencing the flow of events" (Parker \& Braithwaite 2003: 119). We think of tax as something that people pay automatically or that tax inspectors make people pay: It is a static, stultified, coercive, and impersonal exchange, on a par with handing over money to a cashier when we buy goods that we cannot return. Traditionally, taxation has not been conceived as a regulatory arena where both taxpayers and tax authorities need almost continuous shepherding. Yet tax systems have evolved into this form. As the articles in this issue show, most people do not have much understanding of what tax laws mean and why the tax system is structured and administered as it is. Yet their compliance depends on their self-discipline and commitment to

Address correspondence to Valerie Braithwaite, Regulatory Institutions Network, Australian National University, Canberra 0200 Australia. Telephone: 00612612 54601; e-mail: Valerie.Braithwaite@anu.edu.au. 
the system, because opportunities for straying from the prescribed path are temptingly close at hand.

In the past, tax administrations, like customs and excise authorities, have embraced the organizational identity of a command-and-control operational system to accomplish their mission of catching "the scoundrels" who do not pay their tax. The functionality of this approach across the range of tax enforcement activities, however, is no longer taken seriously for dealing with the complexity of contemporary commerce. Taxpaying is contestable, in terms of how much should be paid, how it should be collected, how it should be enforced, and how well it serves the public interest.

Command-and-control systems of regulation are not built to deal with contestation. Admittedly, governments try to accommodate demand for contestation through formal grievance procedures, and through setting up other bodies to oversee the activities of powerful agencies such as tax authorities. Most democracies have taxpayer ombudsmen, taxpayer advocates, and privacy commissioners to guard against the abuse of tax authority power, but their effectiveness in reining in oppressive action by these authorities is far from guaranteed. In most cases, they swing into action after problems have occurred. Enquiries and hearings are not cost-effective ways of encouraging tax authorities to use their powers wisely. For this reason, responsive regulation has come to be seen in some jurisdictions as a viable alternative for organizing the administration of the tax system, in spite of the fact that it can be resource intensive (Black 1997; Haines 1997).

The Australian Taxation Office (1998) has been an innovator in this venture through developing their Compliance Model, which has since been exported to and adapted by other tax jurisdictions (UK, New Zealand, Timor Leste, Indonesia, and within the U.S., Pennsylvania). The Compliance Model grew out of the administration's realization of a growing gap between the actions that the tax authority could prohibit and punish and the actions that they wanted the taxpaying community to pursue in order to ensure the sustainability of the tax system. It is no small coincidence that responsive regulation was embraced at a time when protection of Australia's tax revenue was a priority, because of the anticipated introduction of a national goods-and-services tax, and concerns about increases in the size of the cash economy and aggressive tax planning. Basically, the Australian Taxation Office needed the cooperation of the Australian public to implement one of the biggest tax reforms in its history.

Responsive regulation requires regulators to be responsive to the conduct of those they seek to regulate in deciding whether a more or less interventionist response is required (Ayres \& Braithwaite 1992). A regulatory pyramid, as illustrated in Figure 1, sets out a series of options that a tax authority might use to win compliance, sequenced from the least intrusive at the bottom to the most intrusive at the top. The idea is that an authority that is legitimate and that is engaging seriously with the democratic will of the people does not need coercion at the top of the pyramid to win compliance in most cases. Taxpayers are aware that coercive power exists and can 


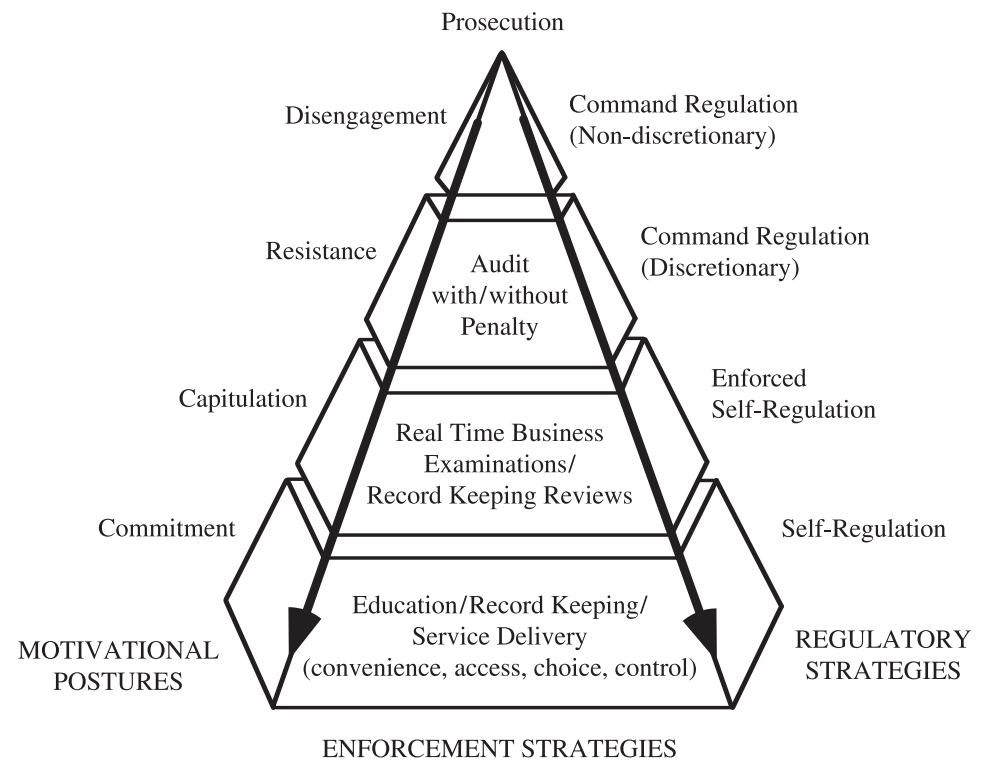

Source: Braithwaite, 2003

Figure 1. Example of regulatory practice with ATO Compliance Model

be used, but generally will comply with persuasion and education. If more encouragement is needed, the level of intrusiveness may be escalated up the pyramid until the intervention elicits the desired response. De-escalation is desirable, once cooperation is forthcoming.

Responsive regulation has several critical elements to its implementation (Braithwaite 2002). It refers to the practice of (a) influencing the flow of events (b) through systematic, fairly directed and fully explained disapproval (c) that is respectful of regulatees, helpful in filling information gaps and attentive to opposing or resisting arguments, (d) yet firm in administering sanctions (e) that will escalate in intensity in response to the absence of genuine effort on the part of the regulatee to meet the required standards. Responsive regulation is a complex business. It welcomes the voice of dissidents, it deliberates on shared community goals and understandings, it enforces agreed upon standards, preferably through teaching, persuading and encouraging those who fall short, but it uses punishment when necessary to achieve its regulatory objectives. It seeks to dismantle any formula that presumes that individuals or groups are uniformly programmed in the way that they will respond to regulatory demands. Tax administrations have traditionally operated on such a relatively simple presumption. Put simply, tax law will influence the flow of events when sanctions are sufficiently certain and severe to offset the gains of not complying with the law.

The Compliance Model does not discount this basic insight, but rather tackles its crudeness. A century of psychology has offered a sophisticated 
array of processes by which individuals come to comply with and defy law, exposing simple cost-benefit analyses as institutionally blunt instruments that are neglectful of individual capacities and rights. The Compliance Model, as a generic application of responsive regulation, takes on board the many sources of influence that contribute to compliance, both from the environment of the regulatee and from the toolbox of the regulator. As shown in Figure 1, the usual tools of the trade for tax officers are there such as real-time enquiries (walk-ins in Waller, this issue), special purpose audits, full audits, prosecution (Braithwaite, Murphy \& Reinhart, this issue), and incarceration if necessary. What has been added to the usual toolbox is a base of activity that involves regulation that is not fear producing in Scholz and Pinney's (1995) terms, but rather duty generating - education, sharing of information and dialogue. Apart from adding to the toolbox, the Compliance Model changes the daily practices of the tax authority away from rule-following procedure and toward the recognition of effort on the part of taxpayers to comply. In other words, tax officers not only note the seriousness of the offense and the threat it poses to the revenue, but also they note the degree to which the offender is critical of his own actions and prepared to make amends. The novel, and essentially challenging, part of responsive regulation, particularly for large bureaucracies such as tax agencies, is tailoring punishment so that a concession is made for self-regulatory effort.

John Braithwaite (2002) has pitted regulatory formalism against responsive regulation. An agency that can list its problems in advance, specify the appropriate response and generate manuals of rules to mandate these responses is structured along formalist lines. The reasons why regulatory responsiveness might be by-passed by tax authorities in favor of regulatory formalism are obvious: process efficiency and outcome consistency. An automatic data-processing function enables tax authorities to process a large number of tax lodgments in a timely, impartial, and fully accountable fashion. In these circumstances, regulatory formalism works well most of the time. This is not to say that the process cannot be finessed through taking on board some of the principles of good regulatory practice developed by such scholars as Bardach and Kagan (1982), Kagan and Scholz (1984), and Tyler (1990). For example, automated letters from enforcement agencies do not have to be couched in legally dense and unfamiliar language, making them incomprehensible to ordinary people, nor do they have to be accusatory and offensive in tone. Regulatory formalism does not preclude fair and respectful treatment of taxpayers (Bentley 1998).

"Humanizing" regulatory formalism, however, is not what responsive regulation is about. First and foremost, responsive regulation is a process that confidently and openly engages taxpayers to think about their obligations and accept responsibility for regulating themselves in a manner that is consistent with the law. The objective of engendering responsibility means that performance of those being regulated can outstrip the expectations and the expertise of the regulator: Regulators can feel like novices at the hands of 
regulatees. Some who are protective of tax office power might well gasp at this point, claiming that this is just what lawyers and accountants who design innovative tax avoidance schemes do. And so they do. But it does not follow from this fact that responsibility is a bad thing to promote in a taxpaying population, nor that responsive regulation is a faulty means for doing so. The very fact that lawyers and accountants are using their talents to undermine the tax system shows the need to not just enforce law, but to come to some agreement about why the law is there and what it means. Responsive regulation creates the space for such discussion to occur. The challenge may not be easy, but it is clear: Can accountants and lawyers be persuaded that taxpaying is a desirable means of supporting a democracy and can they be entrusted to ensure that the process is administered fairly and justly for the collective and for individual taxpayers? Procedural niceties, in the form of treating taxpayers reasonably and respectfully, are important parts of the process of opening channels of communication and dialogue and eliciting good intention, but they do not go as far as responsive regulation in incorporating debate around the fundamental issues of the form that taxation takes and how it impacts on the economic and social fabric of the society.

A second argument for introducing responsive regulatory practices into what has traditionally been a command-and-control system is that with current tax codes, there are many occasions where tax officials need to bring higher-order problem-solving skills to bear on analyzing and understanding the regulatory complexity of a person or firm's taxpaying obligations. They need to show diligence, consult networks, and employ sound judgment in areas such as ambiguous or gray tax law, complaint resolution, and serious non-compliance. In each of these areas, formalists may defend their capacity to deliver consistent, transparent and impartial decisions. But what needs to be considered is that these objectives may be achieved at substantial cost. Taxpayers may judge the decisions as being consistently ill informed, consistently out of touch, consistently unreasonable, and consistently unfair. Advocates of regulatory formalism in taxation thereby run the risk of inadvertently jeopardizing the authoritativeness and legitimacy of the institution in the eyes of the public. It is in these contexts in particular that responsive regulation might make its presence felt in tax administration. Regulatory formalism may impose order on a dispute in the tax domain, but will it promote clarification of what the intention of the law is in the community at large and how that law connects with notions of justice and reasonableness?

The articles in this special issue of Law \& Policy attest to the promise of using responsive regulation in the tax field, as well as revealing challenges in its implementation. The first article, by Sol Picciotto, deals with a fundamental crisis facing tax authorities the world over, the cracks that are appearing in the base of the regulatory pyramid in Figure 1. Picciotto links the indeterminacy of rules with the absence of a shared understanding of how taxation, embodied in law and policy, serves to further the values and ideals of society. 
Without such a shared understanding, tax law loses its meaning, not only because of its complexity, but because it has no legitimate reference point. Picciotto endorses recent appeals for anti-avoidance principles and rules that sit underneath them, but goes further in proposing a more inclusive dialogue in the democracy about the broader principles that should underlie a fair tax system.

Picciotto does not underestimate the difficulties of finding a shared understanding of taxation, a point that is empirically demonstrated by Michael Wenzel in his analysis of the different ways in which tax responsibilities are constructed by people with different social identities. Understandings of what comprises a fair tax system are likely to be very different, depending on whether one adopts an individual identity that is driven by personal ethics that may or may not favor taxpaying, a group identity defined in terms of employment or income level that is driven by self-interest, or an abstract inclusive identity that is driven by collective responsibility. Within the responsive regulatory framework, all the more reason for the inclusive dialogue advocated by Picciotto. With segregation of and competition between interests, the cracks in the base of the pyramid can only worsen.

In the next article, by Gregory Rawlings, the unexpected twists and turns of regulatory dialogue are spelt out as we follow the global conversation on the regulation of offshore financial centers (OFCs). The de facto regulators here are the OECD and the major economic powers. The conflicts are between sovereignty and mobile capital, strong states and weak states, with the shared and noble value of "a level playing field" taking on a range of unexpected meanings in the hands of those defending their interests. The article shows how a responsive regulatory approach can bring different communities together, empower the powerless, and challenge the domination of major economic powers. An undesirable consequence, however, is that there is no agreed and enforced limit to the heights of game playing to which the OFCs and major economic powers can aspire.

While Picciotto, Wenzel, and Rawlings all show the diversity of sensibilities and interests in the taxpaying population, Vivienne Waller moves inside Australia's tax administration to document their struggles with moving from a rule-bound code to one more responsive to taxpayers. Waller examines the walk-in, the objective of which is to check business registration details and establish a cooperative working relationship with small business. The results were not as expected. Tax officers were confused by their "instructions"were they to notice suspicious tax behavior or were they to be literalist about their purpose of only checking registrations? From the perspective of used-car dealers, the purported reason for the walk-in was not credible since government records already provided the requested information. When regulatory action was taken on the basis of suspicions aroused by the visit, Waller draws on Selznick's (1992) notion of integrity to ask what good can come of a process that says it does one thing, then does another. This outcome is an unexpected consequence of introducing responsive regulation 
into a field setting steeped in traditions of compartmentalized regulatory activity and formalism.

While Waller places the microscope on the clash of cultures experienced by field officers, Jenny Job, Andrew Stout, and Rachael Smith take a broader perspective in the next paper and review the stumbling blocks and the points of connection that come into play when responsive regulation is introduced into the tax setting. Drawing on their experiences of introducing responsive regulation to Australia, New Zealand, and Timor Leste, Job and her colleagues document the change in organizational culture required in the move from command-and-control to a responsive style of regulation and discuss the pressures to "translate" core concepts in ways that suit entrenched institutional practices.

Lars Feld and Bruno Frey take up the translation challenge by casting the ideas of responsive regulation within their theoretical framework of the psychological contract between government and taxpayers. Feld and Frey use "crowding theory" to argue that tax morale is best nurtured, not through deterrence strategies, but rather through tax authorities and their governments honoring their side of the contract and providing inclusive, participatory processes for citizens, so that they see decisions being made by a legitimate authority in a fair way. Under these circumstances, tax will be paid even by citizens who do not receive a full public good equivalent to their tax payments. Feld and Frey's article brings us back to Picciotto's point that we need to share an understanding of the purpose of the regulation. Rewards and incentives become viable strategies for regulation, provided they acquire meaning within such a base of shared understanding.

Eliza Ahmed and Valerie Braithwaite's article examines a situation where shared understanding has broken down and feelings of injustice prevail. The case study involves Australia's publicly funded tertiary-education loan scheme, in which students must make loan payments through the tax system once they find employment and receive an income exceeding the threshold. Where students are dissatisfied with their education and critical of the scheme, willingness to pay is lower: An unsurprising finding, except for the link with game playing with tax law and increased tax evasion. The brake on this train of events is holding cooperative social values that promote a sense of community and belief in the tax system. Even the disappointed and disgruntled can, through their belief in doing the right thing, resist the temptation to evade tax.

Responsive regulation assumes that there is a responsible moral self that can be drawn out by a good regulator and that will enable offenders to change their ways and self-regulate more effectively in the future. Using data from the general population and from a group of taxpayers targeted for prosecution through their involvement in mass-marketed tax avoidance schemes, the final article, by Valerie Braithwaite, Katrina Murphy, and Monika Reinhart, identifies three selves that are highly salient among offenders, a self that "thinks morally," a self that "feels oppressed," and a 
self that "takes control" (to the point where the regulator looses control). The challenge for regulators is working out how to draw forward (or reward in Feld and Frey's terms) the self that thinks morally, putting to rest the oppressed self, and entering constructive dialogue with the self that seeks to assert control.

Together these articles show that implementing responsive regulation has been a challenging task for tax authorities. The journey is not complete, but hopefully the articles in this issue generate an appreciation of what a responsive regulatory approach can offer tax administrations as they strive to rebuild institutional integrity and forge their long-term sustainability within a system of democratic governance.

VALERIE BRAITHWAITE was director of the Centre for Tax System Integrity, and is now head of the Regulatory Institutions Network (RegNet) at the Australian National University. Her research focuses on the micro-processes of governance, inclusive democratic practices, and defiance. She is editor of Taxing Democracy: Understanding Tax Avoidance and Evasion (Ashgate, 2003).

\section{REFERENCES}

Australia. Australian Taxation Office (1998) Improving Tax Compliance in the Cash Economy. Canberra: Australian Taxation Office.

Ayres, Ian, and John Braithwaite (1992) Responsive Regulation: Transcending the Deregulation Debate. New York: Oxford Univ. Press.

Bardach, Eugene, and Robert Kagan (1982) Going by the Book: The Problem of Regulatory Unreasonableness. Philadelphia: Temple Univ. Press.

Bentley, Duncan (ed.) (1998) Taxpayers' Rights: An International Perspective. Bond University, Australia: Revenue Law Journal.

Black, Julia (1997) Rules and Regulators. Oxford: Oxford Univ. Press.

Braithwaite, John (2002) Restorative Justice and Responsive Regulation. Oxford: Oxford Univ. Press.

Braithwaite, Valerie (ed.) (2003) Taxing Democracy: Understanding Tax Avoidance and Evasion. Aldershot, UK: Ashgate.

Haines, Fiona (1997) Corporate Regulation: Beyond "Punish or Persuade." Oxford: Oxford Univ. Press.

Kagan, Robert, and John T. Scholz (1984) "The Criminology of the Corporation and Regulatory Enforcement Strategies.” In Enforcing Regulation, edited by K. Hawkins \& J. Thomas. Boston: Kluwer-Nijhoff.

Parker, Christine, and John Braithwaite (2003) "Regulation." In The Oxford Handbook of Legal Studies, edited by P. Cane \& M. Tushnet. Oxford: Oxford Univ. Press.

Scholz, John T., and Neil Pinney (1995) "Duty, Fear and Tax Compliance: The Heuristic Basis of Citizenship Behavior," American Journal of Political Science 39: 490-512.

Selznick, Philip (1992) The Moral Commonwealth: Social Theory and the Promise of Community. Berkeley: Univ. of California Press.

Tyler, Tom (1990) Why People Obey the Law: Procedural Justice, Legitimacy and Compliance. New Haven, Conn.: Yale Univ. Press. 